\title{
DISTINÇÃO MORFOSSINTÁTICA ENTRE VERBOS INERGATIVOS E INACUSATIVOS
}

Paloma Chierici, Iniciação Científica/PRQP/FALE

\section{Introdução}

Esse artigo tem por objetivo realizar uma análise comparativa dos diagnósticos morfossintáticos que contribuem a favor de se subdividir os verbos monoargumentais em duas subclasses distintas, a saber: os inacusativos e os inergativos. Além disso, objetivamos identificar diagnósticos gramaticais adicionais, ainda não apresentados pela teoria gramatical. Para tanto, levaremos em consideração dados disponíveis não só do português, mas também de outras línguas românicas, especialmente dados gramaticais do espanhol. Procuramos ainda mostrar que a subdivisão dos verbos monoargumentais é semanticamente motivada, visto que, em geral, o inergativo s-seleciona um $\mathrm{DP}_{\text {agente }}$ e o inacusativo sseleciona um $\mathrm{DP}_{\text {tema/paciente }}$. Em geral, observa-se que as duas subclasses de verbos ficam apagadas pelo fato de que, na maioria das vezes, o único argumento dos verbos inergativos e dos inacusativos ocupa a posição sintática de sujeito da sentença, i.e. Spec de TP, muito embora sejam gerados em posições de base distintas.

Este artigo está organizado em duas seções principais. Na primeira, conceituaremos os verbos intransitivos, tomando por base a proposta de Perlmutter (1978) e a hipótese inacusativa de Burzio (1986). Na segunda seção, apresentamos os principais diagnósticos morfossintáticos que diferem as duas subclasses, como, por exemplo, o escopo do sufixo agentivo, do particípio absoluto, do clítico dativo de posse, do clítico partitivo no italiano, e do quantificador tudo em $\mathrm{PB}$, dentre outros. $\mathrm{Na}$ última parte, arrolamos as considerações finais. 


\section{A hipótese inacusativa}

Ao contrário dos verbos transitivos que pedem um complemento direto ou indireto, os verbos intransitivos não selecionam complementos. Podemos dizer que, em construções transitivas podem ocorrer, pelo menos, dois argumentos nucleares, enquanto em uma construção intransitiva, existe apenas um argumento nuclear, o que explica a razão pela qual a tradição gramatical denomina os verbos monoargumentais de intransitivos. Consoante Duarte (2004), “construções transitivas permitem a presença de pelo menos dois DPs, ao passo que as intransitivas c-selecionam apenas um". Em (1), abaixo, temos um exemplo de uma construção transitiva e, em (2), de uma oração intransitiva.

(1) João respondeu ao bilhete de José.

(2) João morreu.

Perlmutter (1978) propõe distinguir as classes de verbos intransitivos em inergativos e em inacusativos. Esses dois tipos de verbos têm em comum o fato de requererem apenas um argumento que, sintaticamente, ocupa a posição superficial de Spec de IP (i.e. sujeito da oração). Burzio (1986) irá incorporar a chamada "hipótese de inacusatividade" de Perlmutter, na gramática gerativa, de modo que a distinção entre as duas classes de verbos intransitivos será então formalizada.

Em geral, nota-se que os verbos inergativos são passíveis de serem nominalizados por meio do sufixo derivacional agentivo \{-or; -dor; -ante; -ista, dentre outros\} e sempre selecionam um D/NP na função de agente [cf. Bobalijk (1993)]. Nota-se que os inergativos denotam atividades que dependem da vontade de um agente. São exemplos de verbos inergativos, itens como:

(3) nadar, pular, caminhar, uivar, dançar, surfar, viajar, cantar, trabalhar, mugir, latir, saltar, falar, pescar, bocejar, mentir, correr, respirar, voar, andar, repousar, ronronar etc.

Em (4) e (5) abaixo, encontramos frases com verbos inergativos.

(4) O cão latiu.

(5) João nadou.

Notamos, tanto em (4) como em (5), que o verbo requer apenas um argumento e seleciona um agente, o qual, conforme Cançado (2005), é o 
participante "desencadeador de alguma ação, capaz de agir com controle". Os exemplos abaixo são usados pela autora para descrever o papel temático "agente".

(6) João quebrou o vaso com um martelo

(7) Maria correu.

A autora descreve os papéis temáticos ou funções semânticas que os argumentos desempenham na sentença em (6) da seguinte forma: João, o agente da ação descrita pelo verbo quebrar, o vaso, como o paciente dessa ação; e um martelo, como sendo o instrumento usado pelo agente para desencadear a ação.

Os verbos inacusativos, por sua vez, são aqueles que também selecionam apenas um argumento, mas, ao contrário dos inergativos, não selecionam um agente e sim um D/NP com o papel temático de tema/paciente. Ainda segundo Cançado (2005) tema é "a entidade deslocada por uma ação" e paciente é "a entidade que sofre o efeito de alguma ação, havendo mudança de estado”, conforme se nota em (8) e (9) abaixo.

(8) João jogou a bola para Maria (tema)

(9) João quebrou o vaso (paciente)

São exemplos de verbos inacusativos:

(10) crescer, falir, germinar, ocorrer, vir, chegar, cair, fugir, acontecer, adoecer, aparecer, arder, caducar, cessar, coalhar, decair, decorrer, desabrolhar, desaparecer, desmaiar, emergir, emigrar, evoluir, florir, fugir, mover, ocorrer, partir, pender, ruir, sair, sedimentar, submergir, sucumbir, vagar, vir etc

Em (11) e (12) encontramos frases com verbos inacusativos nas quais podemos verificar que o verbo seleciona um tema ou um paciente.

(11) A chave apareceu.

(12) João fugiu.

As diferenças entre os verbos inergativos e inacusativos também podem ser observadas em virtude da configuração sintática que exibem. Assim sendo, na estrutura em (13) temos a estrutura de um verbo inergativo e, na configuração em (14), a de um inacusativo.

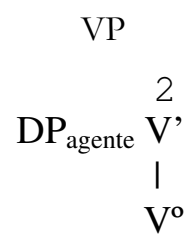




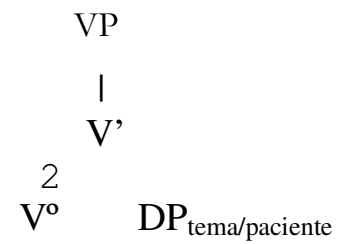

As estruturas sintáticas acima apontam para o fato de que os verbos inacusativos e inergativos possuem comportamento semântico e morfossintático muito distinto. Por essa razão, na próxima seção, mostramos que os dois verbos apresentam comportamento sintático distinto em relação a vários diagnósticos morfossintáticos.

\section{Diagnósticos morfossintáticos}

\subsection{O Quantificador flutuante tudo}

Em Godoy (2005:31), verificamos que o quantificador tudo pode figurar posposto ou não ao verbo em construções inacusativas, conforme ilustram os exemplos abaixo da língua oral.

Os homem chegou tudo.

Os homem tudo chegou.

É importante ressaltar que, nos exemplos acima, o quantificador tudo pode ser substituído por todo como mostramos em (17) e (18).

Os homens chegou tudo.

Todos os homens chegaram.

Essa flutuação do quantificador tudo que pode ocorrer nos verbos inacusativos só é possível quando está quantificando um DP plural. Em (19) e (20) notamos que a flutuação é gramatical por se tratar de um verbo inacusativo e um DP plural. Já em (21) e (22), apesar de serem estruturas inacusativas, a utilização de $\underline{t u d o}$ torna a frase agramatical porque quantifica um NP nu ${ }^{1}$.

As plantinha morreu tudo.

\footnotetext{
${ }^{1}$ De acordo com Saraiva (1997:17) um SN nu é aquele SN constituído somente do nome comum (núcleo) na sua forma básica, sem marca de plural.
} 
As plantinha tudo morreram.

(21) $*$ O menino tudo chegou.

(22) $*$ O menino chegou tudo.

Portanto, podemos dizer que a flutuação do quantificador "tudo" é possível quando se trata de uma estrutura inacusativa com um DP plural. Por sua vez, notase que o quantificador tudo, quando tem escopo sobre o $\mathrm{DP}_{\text {agente }}$ de um verbo inergativo, não pode vir flutuando ao final da sentença, conforme se verifica nos exemplos abaixo.

?As menina correu tudo.

(24) ?Os atleta nadou tudo.

Estruturas como em (23) e (24) não são tão naturais e precisam de uma entonação especial para serem compreendidas. Ao passo que em (25) e (26), em que tudo aparece antes do verbo, não há problemas de interpretação.

Os cachorro tudo uivou.

(26) Os menino tudo cantou.

De acordo com Godoy (2005:32), isso ocorre pelo fato de os verbos inergativos compartilharem características com a dos verbos transitivos em que tudo posposto ao verbo refere-se ao objeto e não ao sujeito, como fica evidenciado pelas sentenças transitivas abaixo.

Os menino ${ }_{j}$ olhou [para as menina $a_{i}$ tudoi].

(28) Os cachorroj comeu [os osso ${ }_{\mathrm{i}}$ tudoi].

(29) As cozinheiraj fez [as receitai tudoi].

Nos exemplos de (27) a (29), tudo quantifica o argumento interno da oração transitiva. Nos exemplos abaixo, apesar de serem estruturas com verbo intransitivo, mais especificamente um inergativo, o tudo parece não quantificar o sujeito da oração, mas sim o objeto "profundo".

(30) ?As criançaj nadou [DP (o nado $\left.{ }_{i}\right)$ tudo $\left._{i}\right]$.

(31) ?Os cavalo saltaram [Dp (o salto) tudo].

(32) ?As moça dançou [Dp as música tudo].

Sendo assim, parece que a flutuação do quantificador tudo, que possui escopo orientado ao DP sujeito da sentença, é mais aceitável quando o verbo possui a estrutura de inacusativo e menos aceitável quando o verbo possui a configuração de 
um verbo inergativo, visto que só os primeiros c-selecionam um argumento interno na sintaxe estrita.

Na próxima seção vamos falar sobre o operador de negação nada que parece co-ocorrer no final da sentença, apenas com os verbos inergativos.

\subsection{O operador de negação nada}

Ao contrário do que ocorre com o quantificador universal tudo, o item de negação universal nada parece que não pode flutuar sozinho ao final de sentença com os verbos inacusativos, mas pode co-ocorrer com os inergativos como mostramos nos exemplos abaixo:

(33) Ele não trabalhou nada.

(34) Ele não nadou nada.

(35) Ele não dançou nada.

(36) ?As cartas não chegaram nada.

(37) ?Os fatos não ocorreram nada.

(38) ?Os livros não caíram nada.

O intem de naegação nada nos exemplos arrolados em (33) a (35) parece ter sentido diferente dos apresentados em (36) a (38). Nos exemplos com verbos inergativos, o nada expressa algo que tem a ver com quantidade. Assim, nesses exemplos, nada indica que não houve nenhum trabalho, dançam, nado ou que a realização dessas tarefas foi muito pequena.

Já nos exemplos de (36) a (38), com verbos inacusativos, o nada parece apenas reafirmar a negação feita pelo não. Tais intuições ficam mais visíveis quando retiramos das orações a partícula não, como mostramos abaixo.

(39) Ele trabalhou nada.

(40) Ele nadou nada.

(41) Ele dançou nada.

(42) *As cartas chegaram nada.

(43) *Os fatos ocorreram nada.

(44) *Os livros caíram nada. 
Parece que o nada tem escopo sobre o objeto abstrato que não está realizado foneticamente, mas está lá no nível de $\mathrm{LF}^{2}$, i.e. na forma de representação abstrata/semântica. Tomando por base o contraste acima, proporemos a hipótese de que o item nada nega o vestígio do DP objeto que se incorporou ao verbo temático na concha v-VP, conforme indicamos pelas representações abaixo.

Ele não trabalhou [Dp nada tobjeto ] (= não fez nenhum trabalho).

Ele não nadou [DP nada tobjeto ]. (= não fez nenhum nado).

Ele não dançou [Dp nada tobjeto ]. (= não fez nenhuma dança).

$\mathrm{Na}$ próxima seção, continuaremos abordando a distinção entre verbos inergativos e inacusativos, discutindo a questão do objeto incorporado.

\subsection{O objeto incorporado}

Os dados arrolados na seção anterior nos permitem identificar um novo diagnóstico que motiva a divisão dos verbos intransitivos em inacusativos e inergativos. Conforme já observamos, o item de negação universal nada parece figurar posposto apenas a verbos inergativos por ter escopo sobre um objeto que não está realizado foneticamente. Da mesma forma, o quantificador universal tudo, quando posposto ao verbo inergativo, tem escopo sobre um provável objeto. Sendo assim, a possibilidade que existe é tratarmos os inergativos como transitivos implícitos, os quais possuem um objeto incorporado na estrutura sintática. Sendo assim, a frase em (42) teria uma configuração como a proposta em (49).

Os agricultores pescaram.

${ }_{\text {Os agricultores }}$
2
$\mathrm{~V}^{2}$

\footnotetext{
${ }^{2}$ Consoante Mioto (2005:26) "Vamos considerar, bastante ingenuamente, que uma sentença é uma sequiência de sons - cuja representação abstrata é PF (Forma Fonética, do inglês Phonetic Form) - e que, além da representação fonética, ela tem um determinado sentido estrutural - cuja representação abstrata é LF (Forma Lógica, do inglês Logical Form)". Assim, podemos dizer que LF (logical form) é uma representação abstrata que contém um determinado sentido estrutural e uma certa estrutura.
} 


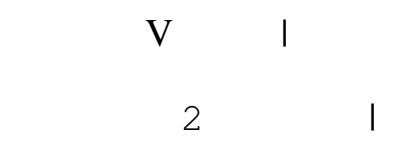

pescaram i

Vale ressaltar que, de acordo com Saraiva (1997:51), quando há a incorporação do objeto, sintaticamente o verbo realiza sem o complemento, uma vez que, na Língua Portuguesa, não existe a incorporação morfológica. Contudo, há a incorporação no âmbito do componente semântico. Ao passo que o português apresenta semanticamente a incorporação do objeto ao verbo, em outras línguas essa incorporação se dá morfologicamente ${ }^{3}$.

Adicionalmente, uma forte evidência de que os inergativos, de fato, possuem incorporação do objeto se verifica em exemplos nos quais podemos parafraseá-los inserindo o objeto na posição de argumento interno do verbo leve "dar". Vejam, por exemplo, o contraste abaixo, em que o objeto cognato é possível com verbos inergativos, conforme mostramos de (50) a (52) abaixo, enquanto, com os verbos inacusativos em (53) e (54), não é possível a inserção de um objeto.

João deu uma gargalhada.

José cantou um canto.

Maria deu uma corrida.

*Gustavo deu uma nascida.

*Paulo morreu uma morte.

$\mathrm{Na}$ próxima seção, vamos discutir como ficam as estruturas dos verbos inacusativos e inergativos com o particípio absoluto.

\subsection{O particípio absoluto}

Outro diagnóstico que nos permite observar a diferença entre os verbos inacusativos e inergativos é a construção com o particípio absoluto, que, segundo

\footnotetext{
${ }^{3}$ Em algumas línguas indígenas como o Tenetehara, a incorporação do objeto ao verbo não é apenas semântica e forma um novo vocábulo. Como, por exemplo, o verbo inergativo "cumprimentar" é a junção das palavras "mão + pegar".
} 
Duarte (2004), é uma "estrutura que corresponde a uma oraşão reduzida dependente de uma oração principal normalmente situada a sua direita". Estruturalmente é formada pelo particípio passado do verbo lexical, seguido ou não do seu argumento interno (AI). Vale ressaltar que nessas construções, o argumento interno equivale ao objeto direto da oração, como mostramos abaixo.

(55) Maria passou as roupas.

(56) [particíio absoluto Passadas as roupas], Maria dormiu.

(57) * * particíio absoluto Passada Maria] ...

Para permitir a gramaticalidade em construções como as exemplificadas acima, são utilizados apenas D/NPs na posição de argumentos internos, e são exatamente os verbos inacusativos que c-selecionam esses argumentos, ao contrário do que ocorre com os verbos inergativos. Nos exemplos abaixo, arrolamos mais exemplos em que os argumentos internos dos verbos inacusativos figuram na posição pós-verbal.

(58) [particípio absoluto Movido o móvel], João passou.

(59) [particípio absoluto Ocorrido o fato], Junior foi embora.

Em (58) e (59), por se apresentarem após o verbo em construções com particípio absoluto, os argumentos internos dos verbos inacusativos dão a impressão de que são sempre gerados na posição de objeto. Sendo assim, apenas verbos da classe dos inacusativos podem figurar em construções com particípio absoluto, pois apresentam o DP na posição sintática de argumento interno. Se por um lado as construções com particípio absoluto são gramaticais com verbos inacusativos, por outro, podemos notar que há problemas nessas construções quando se trata dos verbos inergativos, conforme os exemplos abaixo.

(60) *[particípio absoluto Nadado o atleta $]$....

(61) * * particípio absoluto Uivado o lobo] ...

Essas construções não são possíveis porque os verbos inergativos só cselecionam um argumento nuclear externo, em geral com o papel temático de agente. Logo, construções como em (60) e (61) são agramaticais, uma vez que o argumento do verbo inergativo é gerado como argumento externo de VP. Sendo assim, consoante Mioto (2001), "só os verbos como acabar ou chegar, que têm argumento 
interno, podem figurar numa construção de particípio absoluto". Será, então, essa restrição que impedirá os verbos inergativos de figurarem nessas construções. Na próxima seção, falaremos sobre o sufixo derivacional agentivo que permitirá construções como: cozinheiro, nadador, dançarina etc.

\section{4. $\mathrm{O}$ sufixo agentivo}

Outra característica que difere os verbos inergativos dos inacusativos são as nominalizações com sufixos agentivos (-or, -dor, -ante, -ina, -ista etc).

Se, para os verbos inacusativos, nominalizações que envolvam sufixo agentivo são agramaticais, para os verbos inergativos, elas são perfeitamente aceitas, como podemos observar nos exemplos abaixo.

nadar nadador

correr corredor

(62b) dançar dançarina

(62c) surfar surfista

(62d) cozinhar cozinheiro

Como o argumento externo do verbo inergativo é um agente, as nominalizações acima são licenciadas pela gramática do português. Como o argumento selecionado pelos verbos inacusativos geralmente recebe o papel temático de tema ou paciente, então esses verbos não poderão figurar com os sufixos derivacionais agentivos \{-or, -ante, -ina, etc\}, conforme se nota pelos exemplos abaixo.

(63) vagar *vagador

(64) adoecer *adoecedor

(65) morrer *morredor

(66) desmaiar *desmaiador

Tomando por base a análise dos dados acima, a hipótese que entreteremos neste artigo é a de que verbos inacusativos não podem receber sufixos agentivos porque não s-selecionam um argumento com o papel temático [+AGENTE]. 
$\mathrm{Na}$ próxima seção, continuaremos mostrando diagnósticos que estimulam a divisão dos verbos intransitivos em duas subclasses. Falaremos sobre o clítico dativo de posse e sobre o clítico ne da língua italiana.

\subsection{O clítico dativo de posse e o clítico $\underline{\text { ne }}$}

Outro diagnóstico que nos permite identificar os verbos inacusativos trata-se do comportamento morfossintático do clítico dativo de posse. Em geral, esse clítico só pode vir cliticizado a verbos transitivos e inacusativos, visto que só existe a possibilidade de esse clítico mover-se a partir de um DP que seja argumento interno (de verbos transitivos e inacusativos). Consoante Duarte (2005:2), "O clítico de posse só pode ser movido a partir de um DP que seja complemento do verbo". Assim sendo, os exemplos abaixo mostram a possibilidade de ocorrência do clítico de posse em verbos inacusativos.

(67) Chegou-me as roupas.

(68) Cresceu-lhe a barriga.

(69) Nasceu-lhe uma espinha na testa.

(70) Apareceram-lhe os filhos.

(71) Caiu-lhe os dentes.

As frases acima nos mostram que o clítico tem escopo sobre DPs sujeitos dos verbos inacusativos, visto que os sujeitos são, ao final das contas, o argumento interno do verbo leve na concha $\mathrm{v}$-VP. Este fato constitui, assim, mais um interessante diagnóstico que nos permite diferir verbos inacusativos dos verbos inergativos.

Por fim, verificamos que, diferentemente do que ocorre com os verbos inacusativos, os inergativos nunca podem figurar com o clítico dativo de posse, este último tendo escopo sobre o $\mathrm{AE}$, conforme mostramos abaixo.

(72) * Os lobos lhe uivaram.

(73) *A menina lhe nadou.

Também podemos observar que, em italiano, o clítico partitivo ne pode pronominalizar a partir de um D/NP argumento interno de um verbo transitivo e intransitivo. Isso só é permitido se restar um elemento do tipo quantificacional, 
como molti, tanti ou numerais como due ou tre, em posição de objeto do verbo, conforme os exemplos abaixo retirados de Mioto (2002).

(74) Gianni inviterá [molte ragazze].

(75) *(Di ragazze) Gianni nei parlato a [molti $\left.\mathrm{t}_{\mathrm{i}}\right]$.

No entanto, para que frases como em (74) sejam gramaticais, é necessário que os sintagmas nominais sejam argumento interno. Lembramos mais uma vez que os verbos inacusativos selecionam um argumento interno, logo, é previsível que esses verbos aceitem a cliticização do ne como mostramos abaixo.

(76) $\mathrm{Ne}_{\mathrm{i}}$ sono crirati tanti $\mathrm{t}_{\mathrm{i}}$.

Assim como acontece com o clítico em português, em que seu uso em construções com estruturas inergativas não é possível, o clítico ne partitivo da língua italiana também não pode ocorrer com verbos inergativos. Por exemplo, em (77) e (78), nota-se que é impossível a cliticização do ne a partir do argumento externo do verbo inergativo.

*(Di ragazze) [tante ___ ] ne hanno invitato Gianni.

(78) *(Di ragazze) ne hanno invitato Giane [tante ].

Conquanto as frases acima possuem um elemento quantificional (tante), não é possível a cliticização do ne, já que este quantificador opera sobre o argumento externo do verbo inergativo.

$\mathrm{Na}$ seção seguinte, mostraremos como a posposição do sujeito é mais produtiva com verbos inacusativos.

\subsection{Sujeito Posposto}

Como vimos anteriormente, o sujeito dos verbos inergativos é gerado na posição canônica de sujeito, resultando na ordem [SV]. Já o sujeito dos verbos inacusativos é gerado na posição de argumento interno, de modo que a posposição do sujeito ocorre com mais freqüência com verbos inacusativos do que com os inergativos, como mostram os exemplos abaixo:

(79) Morreram vinte pessoas.

(80) Chegou uma carta. 
Apareceu uma barata aqui em casa.

As frases com verbos inacusativos de (79) a (81) apresentam o sujeito posposto, o que não interfere na gramaticalidade dos sintagmas. No entanto, frases com verbos inergativos, como em (82) a (84), o sujeito posposto não é muito produtivo, ficando a sua ocorrência restrita a contextos marcados, possivelmente nas situações de focalização do predicado.

?NADOU o atleta.

?TRABALHOU a secretária.

?LATIU o cachorro.

$\mathrm{Na}$ seção seguinte, arrolaremos dados de línguas que selecionam verbos auxiliares diferentes para inergativos e inacusativos.

\subsection{Seleção de verbos auxiliares}

Outro diagnóstico que podemos usar para distinguir os verbos inergativos e os inacusativos é a seleção do auxiliar que algumas línguas fazem em tempos perfeitos. Enquanto os Inergativos selecionam Haver os inacusativos vão selecionar ser. Vejamos alguns exemplos.

Em italiano os inacusativos vão selecionar essere (ser) e os inergativos avere (haver). Em (85) e (86), temos exemplos de verbos inacusativos em italiano, selecionando o auxiliar essere. Já em (87) e (88), os exemplos são de verbos inergativos e, portanto, o auxiliar selecionado é avere.

(85) Tanti ragazzi sono arrivati.

(86) Mario è andato a casa.

(87) Tanti ragazzi banno lavorato.

(88) Gianni $a$ corso.

O holandês também segue essa seleção. Assim, os inacusativos vão selecionar o auxiliar equivalente a ser (zijn) e os inergativos o equivalente a haver (Hebben). Esse fato também ocorre em línguas como o francês, o alemão e o espanhol antigo ${ }^{3}$.

\footnotetext{
${ }^{3}$ Na próxima seção, mostraremos exemplos de como ocorre a seleção dos verbos auxiliares no espanhol antigo.
} 
Com isso percebemos a seleção do auxiliar constitui mais um diagnóstico para motivar a divisão dos verbos monoargumentais em inacusativos e inergativos.

$\mathrm{Na}$ seção 2.8, vamos identificar alguns diagnósticos dos verbos inacusativos e inergativos na língua espanhola tais como construções com particípio absoluto, o uso da partícula $\underline{s e}$ impessoal no pretérito e o ocorrência do sufixo agentivo.

\subsection{Diagnósticos na Língua Espanhola}

Em espanhol também é possível arrolar características que diferem os inacusativos dos inergativos. Uma comprovação dessa diferença é que na Língua Espanhola assim como no português, a construção do particípio absoluto só é possível em estruturas inacusativas, como mostramos abaixo.

(89) Crecidos los niños, vamos a viajar.

(90) Salido el sol, vamos a la playa.

Outra característica dos verbos inacusativos em espanhol é que, com esses verbos, não é possível usar os sufixos -dor e -tor, os quais implicam a noção de um agente.

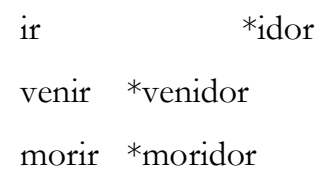

Outra propriedade que os inacusativos apresentam em espanhol é o uso da partícula se impessoal no pretérito, como apontado em abaixo.

(94) ?Se llegó temprano a la escuela ayer.

(95) ?Se creció muy deprisa.

(96) ?Se apareció demasiado tarde.

Apesar de não haver restrições no uso do $\underline{s e}$ com verbos intransitivos, a ocorrência do $\underline{s} \underline{e}$ com verbos inacusativos não parece ser muito aceita por não parecer muito natural.

Também em construções inergativas do espanhol, não é possível o uso do particípio absoluto, como podemos observar em (97).

*Ladrados los perros ... 
Em (98) e (99), podemos verificar que os verbos inergativos em espanhol aceitam livremente o uso do sufixo agentivo $\{$-dor $\}$ e $\{$-tor $\}$.

trabajar tabajador

correr corredor

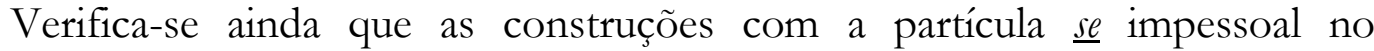
pretérito é mais natural com os verbos inergativos em espanhol, conforme mostramos pelos exemplos abaixo.

(100) Se trabajó mucho ayer.

(101) Se cantó toda la noche.

(102) Se Lloró un mar.

Parece que a possibilidade de a partícula impessoal $\underline{s e}$ poder figurar com verbos inergativos, e não com verbos inacusativos, se deve à ausência de um agente nesse último verbo. Uma possibilidade existe de que clítico se, nesses contextos, fazer referência a um $\mathrm{DP}_{\text {agente }}$ que foi omitido do discurso.

Mais um diagnóstico que podemos observar na Língua espanhola é a seleção do verbo auxiliar ser em construções com verbos inacusativos. Essa seleção só ocorre no espanhol medieval até o século XVI.

Observamos que no espanhol antigo, são os verbos inacusativos no particípio que fazem a seleção do verbo auxiliar ser para formar tempos compostos. Como mostram os exemplos abaixo com os verbos contecer, fallir, parecer e ir (acontecer, falir, aparecer, ir) ${ }^{4}$.

(103) yo por las auersidades que me son contecidas ayna me ensanyo (Conqueridores-II, 42v)

(104) e quando el fierro e el azero les fue fallido fizieron armas de oro (Conqueridores-II, 239r)

(105) Et el Sol sera parescido todauia sobre la faz de la tierra andando aderredor dell orizon (Albateni, $7 \mathrm{v})$

(106) Qvando te demandaren por messageros o por los que son idos en carrera si llegaran a aquel logar o uan o non (Judizios, 41r)

Apesar dessas construções serem possíveis apenas com participio e como mostramos em outras seções que apenas os verbos inacusativos permitem esses

\footnotetext{
${ }^{4}$ Os exemplos foram retirados de ELVIRA, Javier (2001). Intransitividad escindida en español: el uso auxiliar de ser en español medieval. Estudios de Lingüística. Universidad de Alicante.
} 
tipos de construcões, outros exemplos nos mostram que os verbos inergativos também podiam selecionavam um auxiliar, porém era mais comum que esse verbos selecionassem Haver e não ser. Como mostramos em (107) com o verbo correr.

(107) Et auien corrida ya toda essa tierra. (España-II, 72v)

$\mathrm{Na}$ próxima seção apresentaremos as considerações finais.

\section{Considerações finais}

Vimos, neste trabalho, alguns diagnósticos que nos permitem fomentar que os verbos intransitivos são uma classe heterogênea, constituída de lexemas apresentando diferentes propriedades semânticas e sintáticas. Em síntese, vimos que os diferentes diagnósticos morfossintáticos apresentados nos permitem alocar a classe de verbos monoargumentais, em pelos menos duas subclasses: a dos inacusativos e a dos inergativos.

\section{Referência Bibliográfica}

CANÇADO, Márcia. (2005) Manual de semântica. Editora UFMG. Belo Horizonte.

DECAT, Maria Beatriz Nascimento. (1981) Diferenças de concordância verbal entre o português falado e o escrito e suas conseqüências para o ensino de redação. UFMG

DUARTE, Fabio B. (2002) Predicados ergativos. Juiz de Fora: UFJF, ms.

(2004) Propriedades morfossintáticas dos verbos intransitivos no português. UFMG.

(2004) Derivando estruturas com clítico de posse em português, ms.

(2005) Predicados Ergativos, Belo Horizonte.

(2006 ) Caso, função sintática e papéis temáticos, Muriaé: Revista Duc in Altum, $15 \mathrm{p}$, no prelo.

ELISEU, André Manuel Godinho Simões (1984) Verbos ergativos do português: descrição $e$ análise. Lisboa, ms.

ELVIRA, Javier (2001). Intransitividad escindida en español: el uso auxiliar de ser en español medieval. Estudios de Lingüística. Universidad de Alicante. 
GODOY, Luisa Andrade Gomes (2005) A palavra tudo como quantificador universal puro no português brasileiro. Belo Horizonte: UFMG.

LÓPEZ, Justo Fernándes (2004). Clasificación sintáctica de los verbos.

LOZANO, Cristóbal (2004). El conocimiento totalmente nativo vs. Casi nativo del orden de palabras en español: ¿Aparente contradicción?. In Villayandre Llamazares, M. (ed). Actas del V Congresso de Lingüística General (vol. 2), pp. 1815-1826. Madrid: Arco Libros.

MIOTO, Carlos; SILVA, Maria Cristina Figueiredo \& VASCONCELLOS, Ruth Elisabeth Lopes (2005) Novo manual de sintaxe. Florianópolis, Insular

RADFORD, Andrew. Syntax: A minimalist introduction. Department of Language and Linguistics. University of Essex. 1997.

SARAIVA, Maria Elizabeth Fonseca. Buscar menino no colégio: a questão do objeto incorporado em português. Campinas, Pontes, 1997.

SILVA, Maria Cristina Figueiredo \& MIOTO, Carlos Sobre a distinção inacusativo e inergativo, a seleção de auxiliares e a distribuição no pronome ne em italiano. Florianópolis : UFSC, 2002, ms. 